\title{
Cryptorchidism: A practical review for all community healthcare providers
}

\author{
Luis H. Braga, MD, PhD;' Armando J. Lorenzo, MD, $M S c^{2}$ \\ 'Department of Surgery, Division of Urology, McMaster University, Hamilton, ON, Canada; '2Division of Urology, The Hospital for Sick Children, Toronto, ON, Canada
}

Cite as: Can Urol Assoc J 2017;11 (1-2Suppl1):S26-32. htrp://dx.doi.org/10.5489/cuai.4343

See related commentary on page S33.

\section{Abstract}

Cryptorchidism is one of the most common congenital anomalies of the male genitalia, occurring in $1 \%$ of boys by the age of one year. Even though the etiology of cryptorchidism is multifactorial, management has evolved with the clear recognition that hormonal treatment is not effective and surgery between 6-18 months of age leads to better testicular outcomes. Diagnostic laparoscopy is considered the standard approach for management of non-palpable testes, and can be combined with one or two-stage orchidopexy, with up to $80-90 \%$ success rates.

This review discusses the natural history of retractile testicles, indications for hormonal treatment and orchidectomy, ultrasound's role as a diagnostic tool, risks of infertility and testicular cancer, and surgical techniques for inguinal and intra-abdominal testes.

\section{Introduction}

Cryptorchidism (or undescended testis [UDT]) is diagnosed in approximately $1 \%$ of boys who reach one year of age and is one of the most common congenital anomalies of the male genitalia. ${ }^{1}$ The mechanism of normal testicular descent has been a matter of scientific interest for centuries. For example, in 1786 when Hunter dissected a human fetus, he described an intra-abdominal testis connected to the inguino-abdominal wall by a ligament, which he called the gubernaculum testis because it appeared to steer the testis into the scrotum. ${ }^{1}$

Although the etiology of cryptorchidism remains poorly understood, management has evolved with the clear recognition that hormonal treatment is largely ineffective and early surgery (prior to 1-2 years of age) leads to better testicular outcomes. Moreover, diagnostic laparoscopy is now a standard approach for non-palpable testes and can be combined with one- or two-stage orchidopexy with up to $90 \%$ success rates.

\section{Purpose}

This review is intended for urologists, surgeons, and other healthcare providers who occasionally see and manage children with UDT within their busy practice. The following questions will be addressed:

1. What is the natural history of retractile testicles and do they ever need surgery?

2. What is the risk of infertility and testicular cancer in a child with UDT?

3. Is diagnostic ultrasound necessary in boys with palpable or non-palpable UDTs?

4. Which boys with UDT would benefit from hormonal treatment?

5. What surgical techniques are available for intraabdominal testes?

6. When should orchidectomy be performed instead of orchidopexy?

\section{Definition of cryptorchidism}

Cryptorchidism means "hidden testis" and is synonymous with UDT. The majority of UDTs are palpable. UDT can be located anywhere between the abdominal cavity and the entrance of the scrotum, usually along its normal path of descent. An ectopic testicle deviates from this normal path of descent and can reside in unsuspected locations, such as the pre-pubic area or the perineum. In general, cryptorchidism is the result of a developmental defect where the testis fails to descend completely into the dependent portion of the scrotum by six months of age.

\section{Physiology of normal testicular descent ${ }^{2}$}

\section{Gonadal differentiation}

Early in gestation, undifferentiated gonads are believed to be bipotential for either gender within the first 3-5 weeks of pregnancy. Differentiation of the testis is initiated by the 
SRY gene located in the short arm of the $Y$ chromosome by Week 7 of gestation. The SRY gene induces Sertoli cells to produce müllerian-inhibiting substance (MIS), which triggers involution of müllerian duct cells. During the eighth week of gestation, testicular androgens produced by fetal testicular Leydig cells and MIS produced by fetal testicular Sertoli cells are responsible for the development of normal male internal genitalia, which is evident by Weeks 10-13 of gestation.

\section{Transabdominal descent}

The transabdominal descent of the testes takes place between 10 and 23 weeks of gestation under hormonal and mechanical direction. The descending testicles move from the urogenital ridge to the inguinal region simultaneously with shortening of the gubernaculum, testicular differentiation, and development of the cremasteric muscle. The Leydig cell produced insulin-like hormone (Insl3 or descendin), which appears to mediate this transabdominal migration. ${ }^{3}$ Its receptor, relaxin family peptide 2 (RXFP2 gene), is expressed on the gubernaculum. ${ }^{3-6}$

\section{Inguinoscrotal descent}

The inguinoscrotal descent occurs between 24 and 34 weeks of gestation. This process is androgen-dependent and relies on testosterone and androgen receptors to orchestrate descent of the testis from the inguinal canal to the scrotum. Androgens act on the genitofemoral nerve, inducing the release of calcitonin gene-related peptide (CGRP), which promotes rhythmic contractions of the gubernaculum, leading to its extension and protrusion into the scrotal sac. ${ }^{1}$ As the gubernaculum testis protrudes towards the scrotum, it pulls the testis down into the same direction. In addition, the processus vaginalis, an evagination of the parietal peritoneum, elongates through the internal inguinal ring between the internal and external oblique muscles, creating a path for the descending testis to reach the scrotum. Once this process is complete, the inguinal canal is dilated by the gubernacular bulb and the testis pushed through the canal by changes in intra-abdominal pressure. Premature boys are more likely to have UDT at birth (up to $30 \%$ ), but many will descend to the scrotum by six months' corrected gestational age.

\section{Causes of UDT}

A disruption in any phase of testicular descent triggered by hereditary, hormonal, anatomical, environmental, or social factors can result in cryptorchidism. ${ }^{7}$ One of the main risk factors for cryptorchidism is low birth weight, which suggests retarded intrauterine growth. Maternal risk factors associated with higher risk of UDT are: low birth parity, use of assisted reproductive techniques, complicated pregnancy (such as pre-eclampsia, peripartum asphyxia, exposure to diethylstilbestrol [an estrogenic compound], and nicotine during pregnancy), and complicated delivery.

Genetic alternations are 17 times more likely in boys with unilateral or bilateral UDT, including mutations in the Insl3 or RXFP2 genes. ${ }^{4,8}$ Cryptorchidism can present as part of chromosomal conditions, for example Klinefelter syndrome. A familial inheritance pattern has also been demonstrated for isolated cryptorchidism. ${ }^{2,8}$ If a father or brother has UDT, the newborn male will have a 4-6 time relative risk of UDT.

Androgen receptor (AR) gene mutations can result in androgen resistance and prevent the inguinoscrotal descent of the testes. If any form of androgen resistance or exposure to estrogens is present during the inguinoscrotal descent, bilateral testicular migration may be hindered, resulting in intersex anomalies.

Babies with congenital urological or abdominal wall malformations, such as hypospadias, bladder exstrophy, prunebelly syndrome, gastroschisis, and omphalocele, are also more likely to have cryptorchidism. ${ }^{1}$

\section{Diagnosis of cryptorchidism ${ }^{1,5,9-14}$}

The following questions should be asked before evaluating a newborn with an UDT: Was the baby premature? Was there maternal use or exposure to hormones during pregnancy? One should also ask about a family history of UDT, other congenital anomalies, precocious puberty, or consanguinity. Boys should be referred to a pediatric urologist/surgeon for evaluation if the testis has not descended by six months of corrected gestational age (i.e., take into account prematurity).

\section{The retractile testis}

The most common clinical challenge is to differentiate a retractile from a "true" UDT. The parent should be asked if they have ever seen the testis in the scrotum, for example when bathing the child. Similarly, previous records should be reviewed, looking for documentation of normal gonad position after birth. Retractile testes are often bilateral and are caused by an overactive cremasteric reflex, which pulls the testis out of the scrotum towards the inguinal canal, particularly when the child is cold or upset. This is a normal condition, although a minority of retractile testes may subsequently settle outside of the scrotum - the so-called "ascending testes." There is controversy as to the incidence, significance, natural history, and management of the ascending testis. ${ }^{15}$ If in doubt, annual followup should be scheduled and orchidopexy considered if the testis has not fully descended before puberty.

Physical examination remains the cornerstone step in making the diagnosis of UDT and distinguishing it from a retractile testis. The child should be examined supine, with 
his legs slightly separated. Hypoplasia of the ipsilateral side of the scrotum suggests a true UDT. With warm hands, the surgeon should examine the size, location, and texture of the contralateral descended testis (if present). The UDT is then sought by gently advancing the fingers along the inguinal canal, sweeping the groin from lateral to medial. The inguinal testis may be felt to pop up under the fingers. If the testis is palpable, one should attempt to bring it down to the scrotum and hold it in the scrotum for about one minute to cause fatigue of the cremasteric muscle. If the testis remains in the scrotum after release, even momentarily, it is not considered as an UDT, but rather a retractile one. However, if it instantly retracts back up, it is considered a true UDT. In overweight children, in whom palpation may be more challenging, sitting cross-legged may facilitate finding the testis. ${ }^{8}$ A true UDT is usually associated with an underdeveloped ipsilateral hemiscrotum (Fig. 1).

\section{Classification}

The most important distinction is between palpable vs. nonpalpable testis. Other terms used to describe the position of the palpable testis are peeping (sliding in and out of the internal inguinal ring), canalicular, extra-canalicular (superficial inguinal pouch), suprapubic (high scrotal/gliding), or ectopic. ${ }^{16}$ Non-palpable testes may be intra-abdominal, absent, atrophic, or inguinal (but difficult to palpate). Intraabdominal testes are usually located just inside the internal ring, but may be anywhere between this anatomical structure and the lower pole of the kidney.

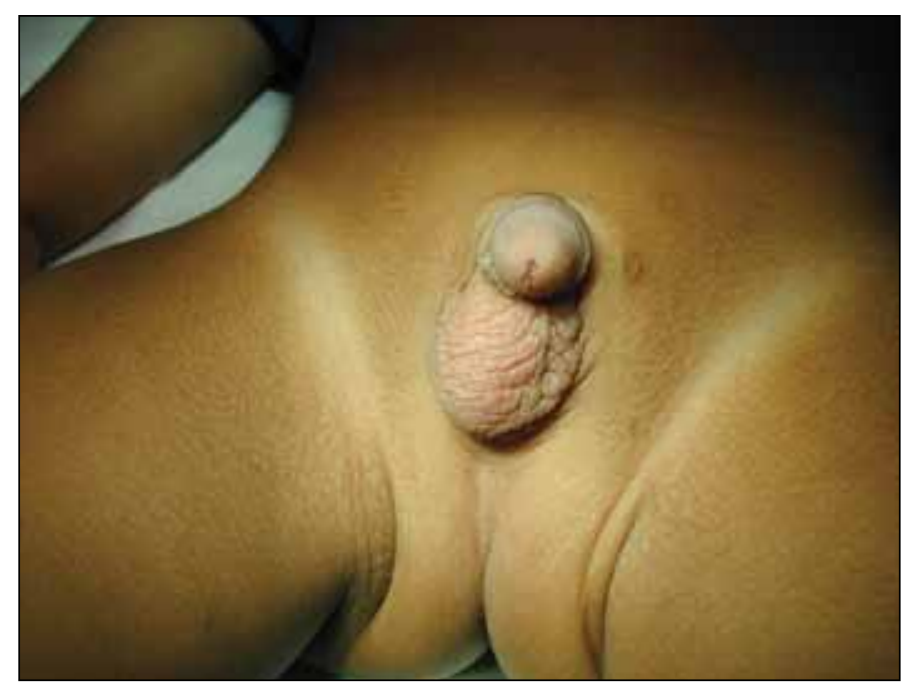

Fig. 1. Left true undescended testis with underdeveloped ipsilateral hemiscrotum - typical finding on physical examination of these boys.

\section{Laboratory investigations}

In cases of unilateral cryptorchidism, blood work is unnecessary. Bilateral non-palpable testes warrant laboratory investigation to confirm the presence of testicular tissue and to rule out a disorder of sexual differentiation. A karyotype should be ordered, along with measurements of follicle-stimulating hormone ( $\mathrm{FSH}$ ) and luteinizing hormone ( $\mathrm{LH}){ }^{2,8}$ After three months of age, a human chorionic gonadotropin hormone (hCG) stimulation test can be performed to evaluate testicular response by measuring testosterone levels. If $\mathrm{LH}$ and $\mathrm{FSH}$ are elevated, but testosterone levels are undetectable, a diagnosis of anorchia can be suspected. In some settings, this can be further confirmed by ordering MIS levels.

\section{Radiographic imaging}

Imaging cannot be recommended as a standard adjunct to preoperative assessment of UDT. Ultrasound can misdiagnose retractile testes as true UDT by triggering a cremaster reflex. Ultrasonography is reported to have a sensitivity of $76 \%$ in the diagnosis of non-palpable testis, but it does not alter its management, therefore it is considered unnecessary. ${ }^{17}$ Ultrasound may, however, be useful in certain circumstances, such as in obese patients. ${ }^{8}$

\section{Clinical indications for treatment}

There are many reasons supporting early surgical intervention for UDT, which is now recommended between six and 18 months of age. ${ }^{1}$ These include reduced fertility, risk of testicular malignancy, testicular torsion or trauma, association with inguinal hernia, and psychological or body image issues.

\section{Reduced fertility}

Any correlation of infertility with UDT must be tempered by the fact that $15-20 \%$ of all couples have difficulty conceiving and there is often more than one factor. Paternity rates are similar to the general population for men with only one affected testis, but are lower (33-65\%) for those with bilateral UDT. ${ }^{2}$ The histology of the UDT is normal at birth and becomes progressively abnormal after one year of age, with $40 \%$ of UDTs losing their germ cells by two years of age. ${ }^{1}$ A randomized study found larger testicular volumes after orchidopexy performed at nine months vs. three years, suggesting that the testis, at least partly, loses its capacity for recovery if placed in the scrotum beyond one year of age. ${ }^{18}$

Based on this histological evidence and the suggestion that early surgery may prevent or reverse it, most pediatric urologists perform orchidopexy around one year of age. The European Association of Urology (EAU) now recommends orchidopexy be performed at the latest by $12-18$ months. ${ }^{5}$ 


\section{Risk of testicular cancer}

Testicular cancer is rare, with an incidence of 4.2/100 000 in Canada. ${ }^{9}$ There has long been an association noted between UDT and testicular malignancy, with up to $11 \%$ of testicular cancers developing in men with a history of UDT. ${ }^{10}$ Recent studies have found the relative risk (RR) of developing testicular cancer in a boy with UDT was 2.7-8, corresponding to an absolute risk of $12-33$ per $100000 .{ }^{19}$ The risk is slightly increased in the normally descended testis. ${ }^{6}$ Performing orchidopexy prior to puberty appears to decrease the RR of subsequent testicular cancer to 2.2 (95\% confidence interval [Cl] 1.6-3.1). ${ }^{11}$ For this reason, it has been recommended that unilateral inguinal and intra-abdominal testes identified after puberty should be removed..$^{5,19}$

\section{Risk of inguinal hernia, torsion, trauma, and psychological distress}

About $90 \%$ of UDTs are associated with a persistent processus vaginalis. An incarcerated hernia may cause ischemia and atrophy to an UDT, so hernias should be repaired when diagnosed and orchidopexy performed at the same time. ${ }^{1}$

Testicular torsion is more common in UDT because the inguinoscrotal attachments are looser (Fig. 2). A testis in the inguinal canal may also be subjected to blunt traumatic injury by compression against the pubic bone.

Psychological distress is more likely in the parents than the pre-pubertal child, so parents should be reassured about the excellent outcomes for fertility and low risk of cancer in boys with unilateral UDT. A teenager with one testicle can be offered a testicular prosthesis.

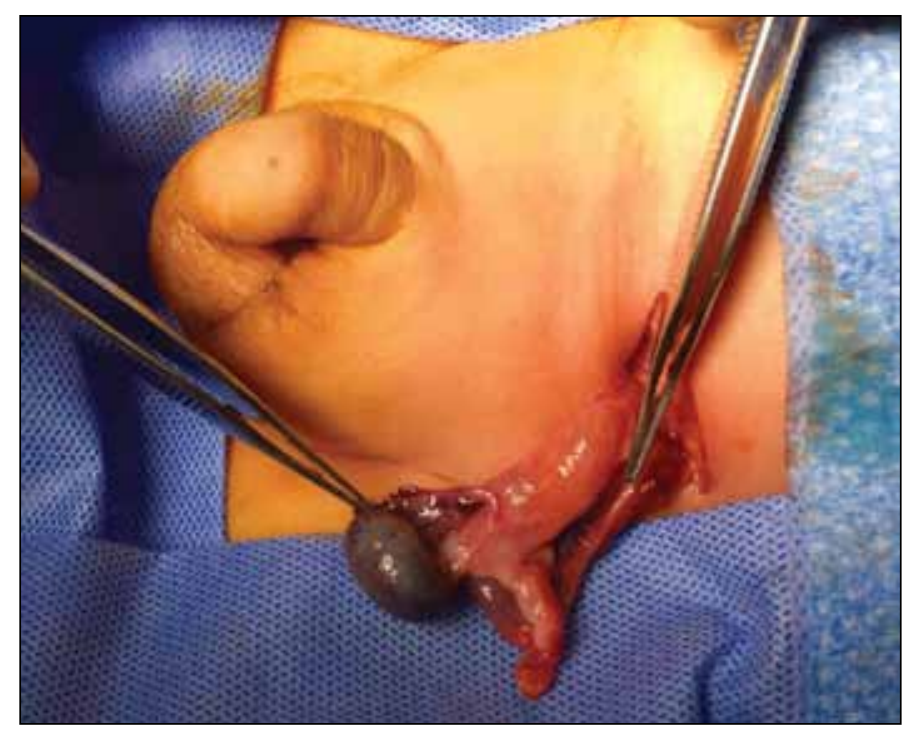

Fig. 2. Testicular torsion on an undescended testis.

\section{Hormone treatment for cryptorchidism}

Boys with unilateral UDT have been treated with hCG, gonadotropin-releasing hormone $(\mathrm{GnRH})$ or $\mathrm{LH}$-releasing hormone $(\mathrm{LHRH})$ with reported testicular descent in only $20 \%$, less so when the testicle is higher. ${ }^{1,5}$ Androgens are not used because they can trigger precocious puberty. Side effects of hCG may include increased scrotal rugae and pigmentation of skin, and increased pubic hair growth and penile growth, with high doses (more than 15000 IU) inducing epiphyseal plate fusion and retarding future somatic growth. Orchidopexy remains the primary gold standard treatment for unilateral UDT. ${ }^{2}$

Hormonal therapy may be considered in bilateral cryptorchidism, to distinguish retractile/ascending testis from undescended testes or to improve collateral testicular blood supply during redo orchidopexy. ${ }^{1}$ Evidence has suggested that intranasal $\mathrm{GnRH}$ may increase the fertility index of the testis if given postoperatively or preoperatively. ${ }^{2,5}$ In most settings, the use of hormones is discouraged, as the improvement is marginal (at best), delays definitive management (surgery), and has unknown long-term impact on testicular development and function.

\section{Surgery for the palpable testis}

Palpable testis should be approached via inguinal exploration. The technical details of the operation are well-described in standard current pediatric surgical and urological textbooks. ${ }^{1,2}$ The key steps of this operation are:

- Mobilization of the testis and the spermatic cord to the level of the deep inguinal ring.

- High ligation of the processus vaginalis.

- Skeletonization of the cord by division of cremasteric and internal spermatic fascia.

- Mobilization of the cord through the internal ring to obtain adequate length to bring the testis to the scrotum without tension. Division of the gubernaculum is optional.

- Placement of the testis in a sub-dartos pouch in the scrotum. If used, fixation sutures should be placed through the tunica albuginea only, not the testicular parenchyma.

A scrotal approach for palpable testicles has been described and favoured by some. ${ }^{12}$ It appears to be most appropriate for high scrotal or ascending testes.

\section{Surgical approach to the non-palpable testis}

If the testis is non-palpable preoperatively, as is the case in $20 \%$ of UDTs, physical examination under anesthesia can sometimes allow identification of the testis. Otherwise, 
diagnostic laparoscopy is the procedure of choice. If laparoscopy is unavailable, an inguinal and, if necessary, abdominal exploration, can be done to find or rule out an intraabdominal testis. However, it could be argued that in settings that lack the equipment or expertise to perform diagnostic laparoscopy, patients should be referred to a centre that has those resources. The surgical findings will either be:

- Blind-ending vas deferens and vessels, indicating a "vanishing testis" and no further need for exploration (10-20\%) (Fig. 3).

- Spermatic cord structures entering the inguinal canal through the internal inguinal ring. Inguinal exploration or scrotal may find an atrophic testis (a.k.a. testicular nubbin), which can be removed, or a healthy testis, amenable to orchidopexy (30\%).

- Intra-abdominal or peeping testis (50\%), which will require either an open or laparoscopic approach.

\section{Inguinal approach to the high inguinal, peeping or intra-abdominal testis}

Bringing a high testicle down to the scrotum while preserving its blood supply can be a formidable surgical challenge. Helpful maneuvers include division of the lateral fibrous attachments of the cord at the internal ring, mobilization of the retroperitoneal spermatic vessels (which are often the main limiting factor) by blunt dissection up to the lower pole of the kidney, and bringing the cord medial to the inferior epigastric vessels (so-called Prentiss maneuver, which unfortunately does not usually add much length). The testis can be fixed in the scrotum even if it causes upward traction of the scrotal skin. If the testis still does not reach the scrotum, one option is to suture it to the pubic tubercle and return in 6-12 months for a second-stage operation. However, the testicular blood supply is at increased risk of injury during a second inguinal procedure.

\section{Fowler-Stephens procedure}

The Fowler-Stephens orchidopexy was originally described as a single-stage, open inguinal approach for the high intraabdominal testes in which the testicular artery and veins are too short to allow the testes to reach the scrotum with a standard orchidopexy. ${ }^{13}$ The Fowler-Stephens technique involves clipping and transection of the testicular vessels with preservation of the collateral arterial flow through the deferential artery and cremasteric vessels. The main risk of this technique is the failure of the deferential artery to supply adequate blood flow, leading to testicular atrophy. The presence of a long looping vas increases that risk (Fig. 4). ${ }^{14}$

Performing the Fowler-Stephens in two stages (first ligating the testicular vessels then performing orchidopexy 6-12

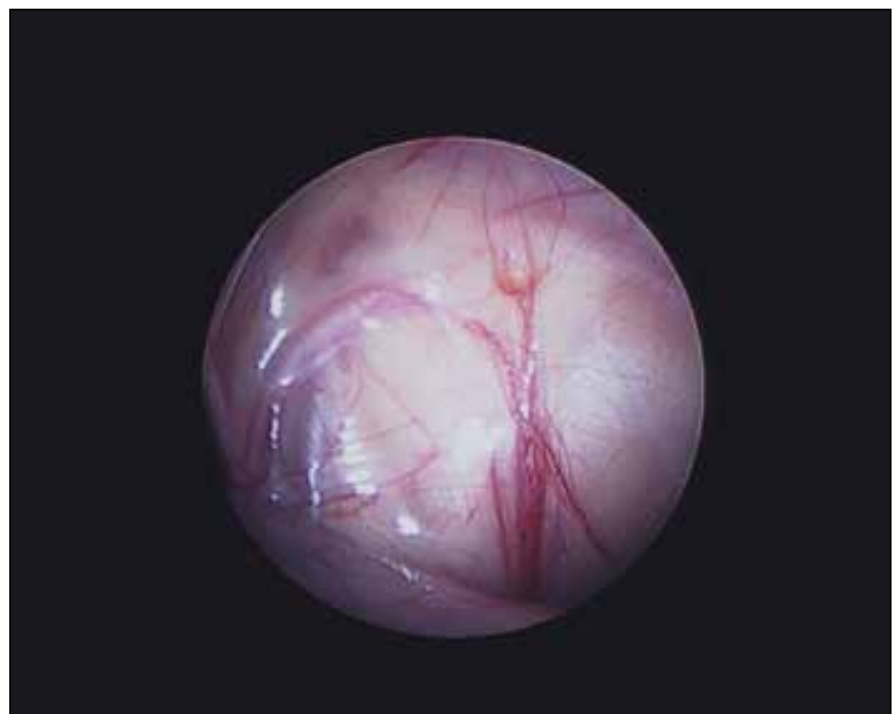

Fig. 3. Laparoscopic view showing blind-ending vas and testicular vessels with hemosiderin deposit, indicative of vanishing intra-abdominal testis.

months later) theoretically allows the collateral blood supply to develop (Fig. 5). Preservation of the gubernaculum also may decrease the likelihood of testicular atrophy. A laparoscopic approach is now widely used for the one- or two-stage Fowler-Stephens orchidopexy. ${ }^{20,21}$

\section{Other surgical findings at orchidopexy}

Most undescended testes have concomitant epididymal abnormalities. An appendix testis or appendix epididymis can be removed. Ectopic adrenal tissue rests are golden yellow and have little significance. Rarely, the vas deferens may be congenitally absent (associated with renal agenesis). Another rare finding is the presence of Müllerian duct remnants (fallopian tubes) associated with UDT and deficiency of MIS.

\section{Complications and outcomes of orchidopexy}

Immediate surgical complications of orchidopexy, such as damage to the vas deferens, wound infection, and hematoma, should be rare. Boys should be assessed at one month after surgery and at 6-12 months to examine for evidence of testicular atrophy or testicular ascent. Testicular atrophy occurs in less than $5 \%$ of boys after unilateral orchidopexy. The risk of atrophy is higher in infants presenting with an associated incarcerated hernia and with intra-abdominal testis. Evidence suggests that early orchidopexy may improve the likelihood of the testis producing sperm, but there is no indication that men with unilateral cryptorchidism have decreased fertility even without surgery. ${ }^{18}$ The cancer risk may be diminished by early surgery, but again, the evidence is weak. ${ }^{11}$

Results of surgery for intra-abdominal testes are better with a one-stage orchidopexy preserving the testicular ves- 


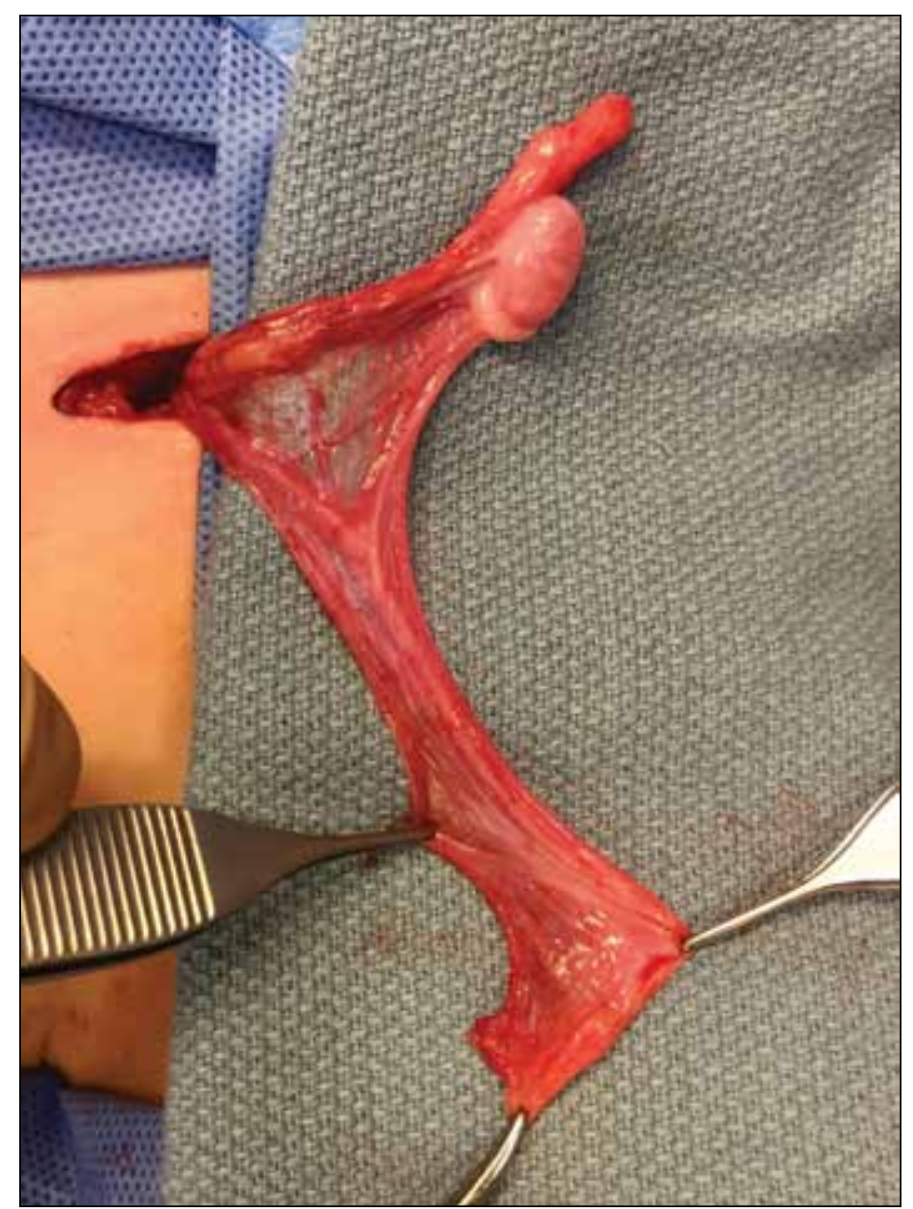

Fig. 4. Appearance of long loop vas deferens, which is rarely associated with undescended testis.

sels, than with the Fowler-Stephens technique. ${ }^{22}$ However, we have seen excellent results with a two-stage FowlerStephens gubernaculum-sparing laparoscopic orchidopexy for intra-abdominal testes, as measured by preservation of testicular blood flow on postoperative Doppler ultrasound. ${ }^{21}$

\section{Suggested treatment algorithm}

\section{Bilateral cryptorchidism after six months of age:}

a. Rule out retractile testes.

b. Consider evaluation for disorders of sex development (DSD).

2. Unilateral palpable testis: Inguinal orchidopexy at 9-18 months of age.

3. Unilateral non-palpable or peeping testis:

a. If available, proceed to diagnostic laparoscopy:

i. No further treatment if vanishing testis (blind-ending vessels).

ii. Inguinal exploration if vessels seen entering internal ring, with orchidopexy or excision of atrophic testis (testicular nubbin).

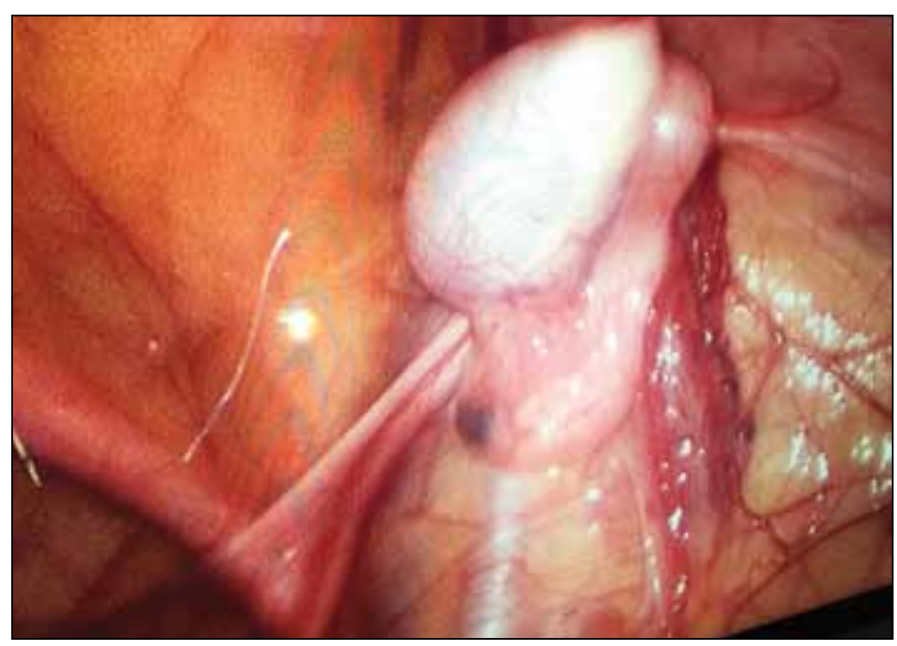

Fig. 5. Laparoscopic view of the abdominal cavity showing intra-abdominal testis with well-developed collateral blood supply (six months post-first-stage Fowler-Stephens laparoscopic orchidopexy) at the time of the second stage.

iii. One- or two-stage Fowler-Stephens orchidopexy, preserving or not the gubernaculum, for intra-abdominal testis.

b. If no laparoscopy:

i. Inguinal exploration plus abdominal exploration if necessary, with primary or staged orchidopexy.

\section{Unilateral undescended testis after puberty: Orchidectomy.}

Competing interests: The authors report no competing personal or financial interests.

This paper has been peer-reviewed.

\section{References}

1. Hutson J. Undescended testis, torsion, and varicocele. In: Grosfeld J, $0^{\prime}$ Neill J, Coran A, et al. Pediatric Surgery, 6th ed. Philadelphia: Mosby Elsevier;2006: p.1193-1205. https://doi.org/10.1016/b9780-323-02842-4.50078-4

2. Barthold J, Hagert J. Etiology, diagnosis, and management of the undescended testis. In: Wein AJ, Kavoussi LR, Partin AW et al. (eds.) Campbell-Walsh Urology, Volume 4, 11th ed. Philadelphia: Elsevier, 2015: p. 3430-52

3. Feng S, Ferlin A, Truong A, et al. INSL3/RXFP2 signaling in testicular descent. Ann N Y Acad Sci 2009;160:197-204. https://doi.org/10.1111/i.1749-6632.2009.03841.x

4. Ferlin A, Zuccarello D, Zuccarello B, et al. Genetic alternations associated with cryptorchidism. JAMA 2008;300:2271-6. https://doi.org/10.1001/jama.2008.668

5. Tekgül S, Riedmiller H, Dogan HS, et al. Guidelines on pediatric urology. EAU Update 2013;11-3.

6. Akre 0 , Pettersson A, Richiardi L. Risk of contralateral testicular cancer among men with unilaterally undescended testis: A meta-analysis. Int J Cancer 2009;124:687-9. Itps://doi.org/10.1002/iic.23936

7. Foresta C, Zuccarello D, Garolla A, et al. Role of hormones, genes, and environment in human cryptorchidism. Endocr Review 2008; 29:560-80. https://doi.org/10.1210/er.2007-0042

8. Kolon TF, Patel RP, Huff DS. Cryptorchidism: Diagnosis, treatment, and long-term prognosis. Urol Clin North Am 2004;31:469-80. htrps://doi.org/10.1016/i.ucl.2004.04.009

9. Chia VM, Quraishi SM, Devesa SS, et al. International trends in the incidence of testicular cancer, 19732002. Cancer Epidemiol Biomarkers Prev 2010;19:1151-9. https://doi.org/10.1158/1055-9965. EPF-10-0031. 
Braga et al.

10. Hutson J. Undescended testes. In: Stringer MD, Oldham KT, Mouriquand P. (eds.) Pediatric Surgery and Urology: Long Term Outcomes, 2nd ed. Cambridge: Cambridge University Press, 2006: p.652-63. https://doi.org/10.1017/CB09780511545757.052

11. Pettersson A, Richiard L, Nordenskjold A, et al. Age at surgery for undescended testis and risk of testicular cancer. N Engl J Med 2007;356:1835-41. https://doi.org/10.1056/NEJMoa067588

12. Bassel YS, Scherz HC, Kirsch AJ. Scrotal incision orchidopexy for undescended testes with or without a patent processus vaginalis. J Urol 2007;177:1516-8. ht1ps://doi.org/10.1016/i.juro.2006.11.075

13. Fowler $R$, Stephens $F D$. The role of testicular vascular anatomy in the salvage of high undescended testes. Aust N Z J Surg 1959;29:92-106. htrps://doi.org/10.1111/i.1445-2197.1959.tb03826.x

14. Dave S, Manaboriboon N, Braga LH, et al. Open vs. laparoscopic staged Fowler-Stephens orchidopexy: Impact of long loop vas. J Urol 2009;182:2435-9. https://doi.org/10.1016/i.juro.2009.07.050

15. Taghizadeh AK, Thomas D. Ascent of the testis revisited: Fact not fiction. BJU Int 2008;102: 676-78. https://doi.org/10.1111/i.1464-410X.2008.07704.x

16. Hack WW, Siistermans $K$, van der Voort-Doedens $L M$, et al. The high scrotal ("gliding") testis revised. Eur J Pediatr 2007;166:57-61. https://doi.org/10.1007/s00431-006-0202-4

17. Elder JS. Ultrasonography is unnecessary in evaluating boys with a non-palpable testis. Pediatrics 2002;110:748-51. ht1ps://doi.org/10.1542/peds.110.4.748
18. Kollin C, Karpe B, Hesser U, et al. Surgical treatment of unilateral undescended testis: Testicular growth after randomization to orchidopexy at age 9 months or 3 years. J Urol 2007; 178: S1589-93. https://doi.org/10.1016/i.juro.2007.03.173

19. Wood HM, Elder JS. Cryptorchidism and testicular cancer: Separating fact from fiction. J Urol 2009;181:452-61. https://doi.org/10.1016/i.juro.2008.10.074

20. Braga LH, DeMaria J. Laparoscopic orchidopexy with or without preservation of cremasteric vessels: Can we reduce atrophy rates? Can Urol Assoc J 2014;8Suppl3:S49.

21. Braga LH, DeMaria J. Laparoscopic orchidopexy preserving the cremasteric vessels and using the inguinal canal as a pathway for testicular descent. Can Urol Assoc J 2009:3Suppl1:S60.

22. Stec AA, Tanaka ST, Adams MC, et al. Orchidopexy for intra-abdominal testes: Factors predicting success. J Urol 2009;182:S1917-20. https://doi.org/10.1016/i.juro.2009.03.069

Correspondence: Dr. Luis H. Braga, Department of Surgery, Division of Urology, McMaster University, Hamilton, 0N, Canada; braga@mcmaster.co 